\title{
Effects of temperature and photoperiod on daily activity rhythms of Lutzomyia longipalpis (Diptera: Psychodidae)
}

\author{
Gustavo BS Rivas ${ }^{1}$, Nataly Araujo de Souza ${ }^{2}$, Alexandre A Peixoto ${ }^{1,3^{\wedge}}$ and Rafaela V Bruno ${ }^{1,3^{*}}$
}

\begin{abstract}
Background: Insect vectors have been established as models in Chronobiology for many decades, and recent studies have demonstrated a close relationship between the circadian clock machinery, daily rhythms of activity and vectorial capacity. Lutzomyia longipalpis, the primary vector of Leishmania (Leishmania) infantum in the New World, is reported to have crepuscular/nocturnal activity in the wild. However, most of these studies applied hourly CDC trap captures, which is a good indicative of L. longipalpis behaviour, but has limited accuracy due to the inability to record the daily activity of a single insect during consecutive days. In addition, very little is known about the activity pattern of L. longipalpis under seasonal variations of average temperature and day length in controlled laboratory conditions.

Methods: We recorded the locomotor activity of L. longipalpis males under different artificial regimes of temperature and photoperiod. First, in order to test the effects of temperature on the activity, sandflies were submitted to regimes of light/dark cycles similar to the equinox photoperiod (LD 12:12) combined with different constant temperatures $\left(20^{\circ} \mathrm{C}, 25^{\circ} \mathrm{C}\right.$ and $\left.30^{\circ} \mathrm{C}\right)$. In addition, we recorded sandfly locomotor activity under a mild constant temperature $\left(25^{\circ} \mathrm{C}\right.$ with different day length regimes: 8 hours, 12 hours and 16 hours).

Results: L. longipalpis exhibited more activity at night, initiating dusk-related activity (onset time) at higher rather than lower temperatures. In parallel, changes of photoperiod affected anticipation as well as all the patterns of activity (onset, peak and offset time). However, under LD 16:08, sandflies presented the earliest values of maximum peak and offset times, contrary to other regimes.

Conclusions: Herein, we showed that light and temperature modulate L. longipalpis behaviour under controlled laboratory conditions, suggesting that sandflies might use environmental information to sustain their crepuscular/ nocturnal activity, as well as other important aspects as mating and host-seeking at appropriate times in different seasons. Our results depict previously unappreciated aspects of the L. longipalpis daily rhythms of activity that might have important epidemiological implications.
\end{abstract}

Keywords: Locomotor activity, Lutzomyia longipalpis, Temperature, Day length, Circadian clock

\footnotetext{
* Correspondence: rafaelav@ioc.fiocruz.br

Deceased

'Laboratório de Biologia Molecular, Instituto Oswaldo Cruz, Fundação

Oswaldo Cruz (FIOCRUZ), Rio de Janeiro, Brazil

${ }^{3}$ Instituto Nacional de Ciência e Tecnologia em Entomologia Molecular

(INCT-EM)/CNPq, Rio de Janeiro, Brazil

Full list of author information is available at the end of the article
} 


\section{Background}

Lutzomyia longipalpis (Diptera, Psychodidae, Phlebotominae) is the main vector of Leishmania (Leishmania) infantum in Latin America, broadly distributed from Mexico to Argentina [1]. In the wild, L. longipalpis is principally active at dusk and during the night $[2,3]$. Our previous results recording the locomotor activity of L. longipalpis under artificial conditions not only confirmed its crepuscular/nocturnal behaviour, but also suggested that bloodfeeding, circadian clock and behaviour are interlinked in this insect vector $[4,5]$. In Brazil L. longipalpis is represented by a complex of cryptic species, which differ in their male mating songs, sex pheromones and molecular markers [6,7]. Hence, in the L. longipalpis sympatric species from Sobral, Ceará, we observed a small temporal difference in their daily activity rhythms [8], suggesting that the well-established crepuscular/nocturnal comportment in this complex might have significant temporal differences. Though our previous results $[4,8]$ have indicated some important characteristics in L. longipalpis behaviour, these studies were performed under a constant mild temperature $\left(25^{\circ} \mathrm{C}\right)$ and a light/dark regime similar to the equinox (LD 12:12; cycles of $12 \mathrm{~h}$ of light and $12 \mathrm{~h}$ of darkness). Several studies in diverse insects have exhibited the ability of behavioural entrainment to seasonal changes of temperature and photoperiod $[9,10]$. It is known that L. longipalpis and Phlebotomines in general are active throughout the year but present higher levels of density coinciding with periods of higher temperatures, humidity and rainfall [11-15]. However, these studies are mainly based on the relation between density and seasonal variations, not taking into account daily rhythms of activity. Therefore, we decided to observe the L. longipalpis locomotor activity patterns under controlled laboratory conditions with different temperature and photoperiods, mimicking seasonal environmental variations. Herein, we display how light and temperature are important environmental factors modulating L. longipalpis behaviour.

\section{Methods}

\section{Insects and locomotor activity recording}

Lutzomyia longipalpis sandflies from a Lapinha (Minas Gerais State, Brazil) laboratory colony were reared as previously described [16]. As former results from our group have demonstrated similar patterns of activity between males and females from the same colony [4], we decided to conduct our experiments with males to preserve the laboratory colony. In order to promote the appropriate entrainment for testing the effect of temperature on locomotor activity, we transferred newly emerged males to an incubator under a regime of LD 12:12, at three different constant temperatures $\left(20^{\circ} \mathrm{C}, 25^{\circ} \mathrm{C}\right.$ and $\left.30^{\circ} \mathrm{C}\right)$ and entrained them during 23 days. To test the photoperiod effect on sandfly behaviour, they were entrained under a constant temperature of $25^{\circ} \mathrm{C}$ but combined with different photoperiods of LD 08:16 (cycles of $8 \mathrm{~h}$ of light and $16 \mathrm{~h}$ of darkness) and LD 16:08 (cycles of $16 \mathrm{~h}$ of light and $8 \mathrm{~h}$ of darkness). The choice of day length was based on several chronobiological studies in many species of insects reviewed in $[9,10]$ allowing comparisons with previously tested photoperiodic regimes. After the entrainment, the sandflies were transferred to individual $5 \mathrm{~mm}$ glass tubes, which were properly sealed with plastic caps at both ends. Inside each tube we provided food ad libitum with sucrose solution soaked cotton (10\%). Afterwards, we placed each tube in the Drosophila DAM5 Activity Monitoring System (Trikinetics Inc., Waltham, MA, USA) to record the locomotor activity as previously described $[4,8]$. When a sandfly goes back and forth within the tube, it interrupts an infrared beam that crosses the tube at its midpoint, and this interruption, detected by the onboard electronics, is added to the tube's activity count as a measure of sandfly movement. Thus, the sandflies were monitored every 30 minutes, for five consecutive days, conserving the artificial regime previously applied in each case. However, due to the high mortality observed during the final days of the experiment, we restricted our analysis to two days valid data of the experiment. Each experiment was repeated twice and the total number of sandflies for each condition varied depending upon the mortality (Figure $1-\mathrm{LD} 12: 1220^{\circ} \mathrm{C}, \mathrm{n}=56 ; 25^{\circ} \mathrm{C}, \mathrm{n}=22$; $30^{\circ} \mathrm{C}, \mathrm{n}=17$ ) (Figure $2-\mathrm{LD} 08: 16, \mathrm{n}=25$; LD 12:12, $\mathrm{n}=$ 22 ; $\mathrm{LD} 16: 08, \mathrm{n}=29$ ). Average values of locomotor activity from all insects in each regime were smoothed, to reduce "noise" (abrupt variations), with a 3-point weighted moving average (weight of 2 for the central time point) and all graphs were plotted with the Excel program (Microsoft). The values depicted on graphs were also applied to estimate the absolute activity of each regime. In order to do so, we calculated the "area under the curve (AUC)" with the GraphPad Prism 5 (Prism, La Jolla, CA).

\section{Daily locomotor activity analysis}

For our analysis, we decided to observe not only the overall locomotor activity, but also each parameter of rhythmic activity during the lights on/off transition (simulating dusk). Thus, we precisely determined the initiation of "dusk"-related activity (onset), the maximum level (peak) and the subsequent sudden drop to basal nocturnal level (offset). To do so, we determined these parameters for each insect observing the average activity of the first two experimental days with the Actogram J Program [17]. The activity onset was defined as the time of first non-zero value of activity followed by a gradual increase of it until the maximal value, which represents the peak activity. On the other hand, the offset was defined as the moment that we observed the first zero value (which depicts half an hour of inactivity) after the peak activity. In order to confirm that any advance or 


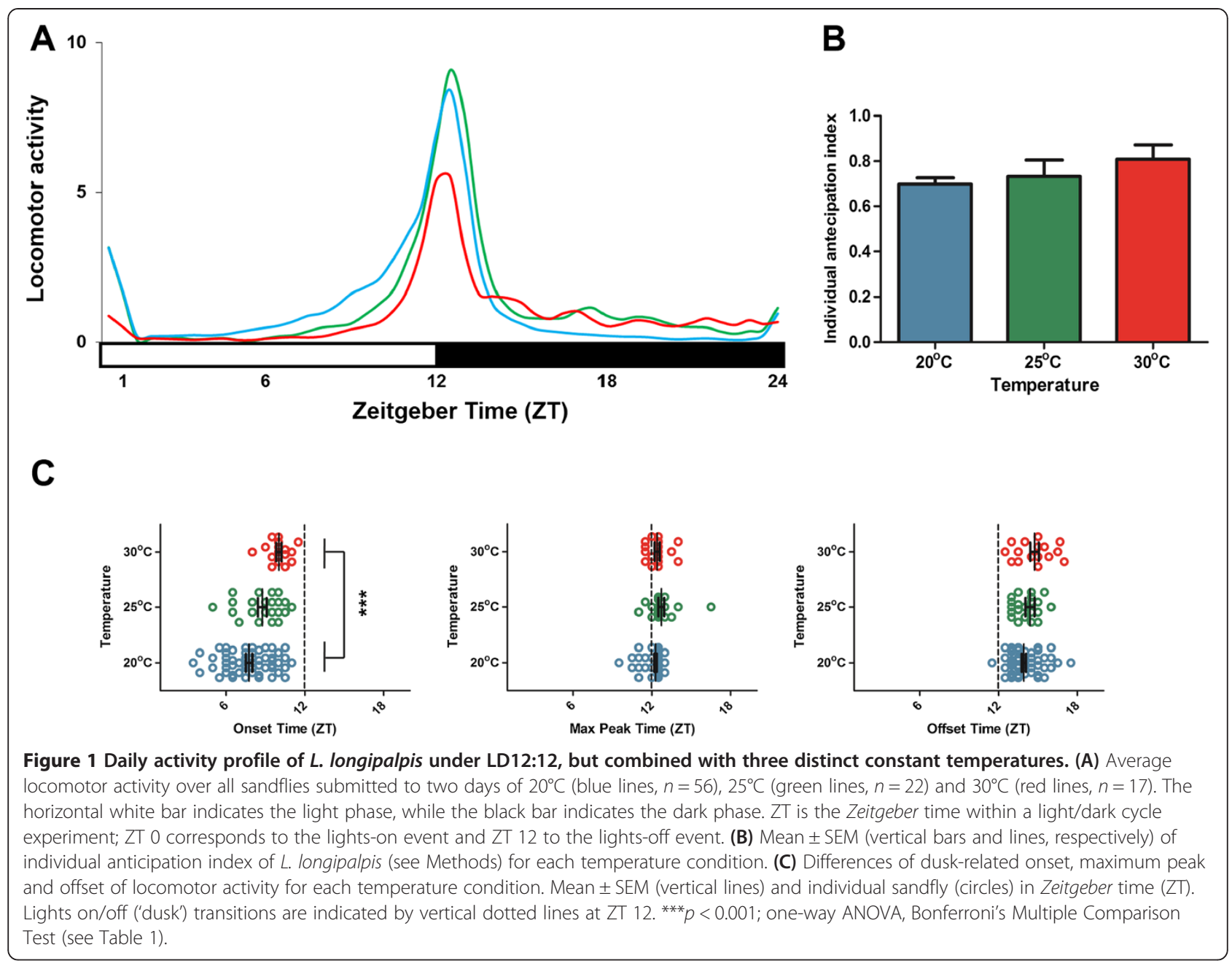

delay of these parameters combined would reflect on changes of anticipation, we evaluated the individual anticipation index, which is obtained by the ratio of the total amount of activity three hours before the lights off (ZT9: ZT12) over the total activity six hours before lights off (ZT6:ZT12) $[18,19]$. Higher values indicate high anticipation, while lower values mean little or no anticipation. In parallel, we also observed the proportion of nocturnal activity dividing the sum of activity recorded during the dark phase by the total amount of it for the whole photoperiod (24 h) [8]. We normalized data by transforming these proportional values with the arcsine square root.

\section{Statistical analysis}

Statistical analysis and graphing were accomplished with the GraphPad Prism 5 (Prism, La Jolla, CA). We compared parameters of three groups (artificial regimes) to test the effect of temperature $\left(20^{\circ} \mathrm{C}\right.$ vs $25^{\circ} \mathrm{C}$ vs $\left.30^{\circ} \mathrm{C}\right)$ and photoperiod (LD 08:16 vs LD 12:12 vs LD 16:08). One-way ANOVA depends on the assumption that the data follow a Gaussian distribution. So, we analyzed each parameter (nocturnal activity, onset time, maximum peak and offset time) with the Shapiro-Wilk normality test $(\mathrm{p}<0.05)$. Only nocturnal activity and onset times passed in the normality test and were analyzed for significance with the OneWay ANOVA (Parametric test). The data of maximum peak and offset time did not pass in Shapiro-Wilk and were analyzed with the Kruskal-Wallis non-parametric test. Simultaneously, we made pairwise comparisons of regimes by two post hoc tests, the Bonferroni's Multiple Comparison Test (parametric) and Dunn's Multiple Comparison Test (nonparametric test).

\section{Results}

Daily rhythms of locomotor activity at different temperature levels

Figure 1 depicts the average activity of $L$. longipalpis at three different temperatures $\left(20^{\circ} \mathrm{C}, 25^{\circ} \mathrm{C}\right.$ and $\left.30^{\circ} \mathrm{C}\right)$. We determined that temperature affects daily activity, considerably altering the proportion of nocturnal activity (Figure 1A and Table 1). At higher temperatures $\left(25^{\circ} \mathrm{C}\right.$ and $\left.30^{\circ} \mathrm{C}\right)$, the sandflies are more active at night than at $20^{\circ} \mathrm{C}$ (Table 1 , 


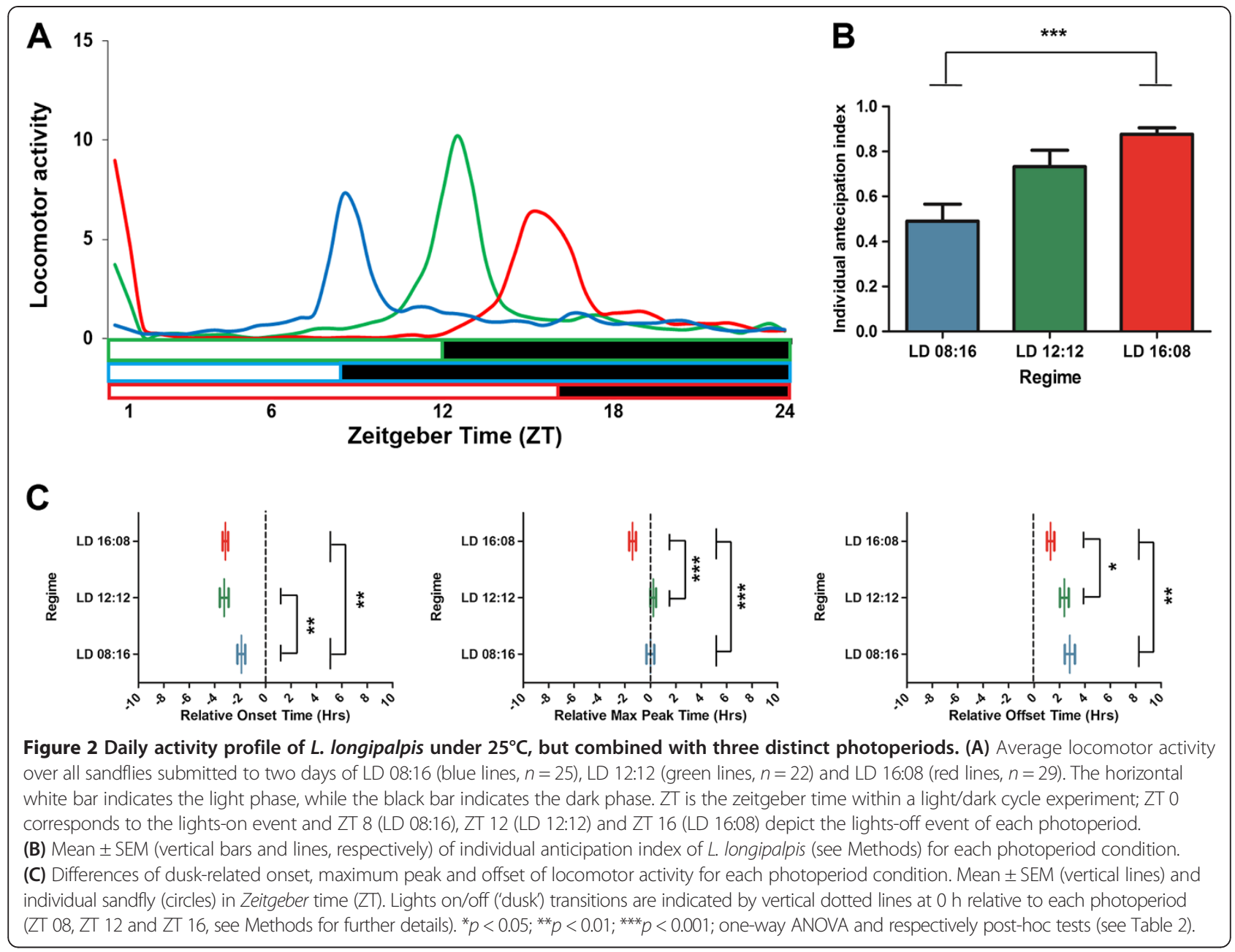

Figure 1A). Also, temperature tends to affect the startle response of maximum peak during lights on/off (1-way ANOVA; $\left.F_{2,94}=5.847 ; p<0.01\right)$. At $30^{\circ} \mathrm{C}$, the maximum peak is considerably lower compared to the other regimes (Bonferroni's Multiple Comparison Test, $25^{\circ} \mathrm{C}$ vs $30^{\circ} \mathrm{C}: t=$ $3.255, p<0.01$ and $20^{\circ} \mathrm{C}$ vs $\left.30^{\circ} \mathrm{C}: t=2.931, p<0.05\right)$.
Although we did not find statistical differences in the anticipation index (Figure 1B), a broader peak as well as lower levels of activity during the night were evident, contrary to the pattern at $30^{\circ} \mathrm{C}$ (Figure $1 \mathrm{~A}$ ). Moreover, there was an earlier onset at $20^{\circ} \mathrm{C}$, while these values were a bit delayed at $30^{\circ} \mathrm{C}$ and intermediate at $25^{\circ} \mathrm{C}$ (Figure $1 \mathrm{C}$,

Table 1 Nocturnal activity (\%), onset, maximum peak and offset time (Zeitgeber Time \pm SEM) and 1-way ANOVA of the experiments depicted on Figure 1

\begin{tabular}{|c|c|c|c|c|c|}
\hline & & Nocturnal activity & Onset time & Max peak time & Offset time \\
\hline \multirow[t]{3}{*}{ VALUES } & $30^{\circ} \mathrm{C}$ & $62.7 \pm 4.2$ & $10 \pm 0.2$ & $12.4 \pm 0.2$ & $14.7 \pm 0.3$ \\
\hline & $25^{\circ} \mathrm{C}$ & $52.3 \pm 3.7$ & $8.7 \pm 0.3$ & $12.7 \pm 0.2$ & $14.4 \pm 0.3$ \\
\hline & $20^{\circ} \mathrm{C}$ & $36 \pm 2.0$ & $7.7 \pm 0.2$ & $12.3 \pm 0.1$ & $13.9 \pm 0.1$ \\
\hline \multirow[t]{4}{*}{ Statistical analysis } & 1-way ANOVA & $F_{2,94}=20.09 \quad P<0.001$ & $F_{2,94}=13.11 \quad P<0.001$ & $H=2.442^{b} \quad P=0.2949^{b}$ & $H=5.636^{b} \quad P=0.0597^{b}$ \\
\hline & $25^{\circ} \mathrm{C}$ vs $30^{\circ} \mathrm{C}$ & $N S^{a}$ & $N S^{a}$ & $N S^{c}$ & $N S^{c}$ \\
\hline & $25^{\circ} \mathrm{C}$ vs $20^{\circ} \mathrm{C}$ & $P<0.001^{\mathrm{a}}$ & $N S^{a}$ & $\mathrm{NS}^{\mathrm{c}}$ & $\mathrm{NS}^{\mathrm{c}}$ \\
\hline & $30^{\circ} \mathrm{C}$ vs $20^{\circ} \mathrm{C}$ & $P<0.001^{a}$ & $P<0.001^{a}$ & $N^{c}$ & $\mathbf{N S}^{\mathrm{c}}$ \\
\hline
\end{tabular}

${ }^{a}$ Bonferroni's Multiple Comparison Test.

${ }^{b}$ Kruskal-Wallis 1-way ANOVA (nonparametric test).

'Dunn's Multiple Comparison Test (nonparametric test). 
Table 1). On the other hand, the peak and offset, in a first moment, seems quite similar under any temperature applied. The maximum peak was attained around half an hour after lights-off and in turn the offset time at two hours after lights-off (Figure 1C, Table 1). Nevertheless, at $20^{\circ} \mathrm{C}$ a number of insects peaked in their activity before lights off (Figure 1C), with a borderline statistical significance on offset time (Table 1), which suggests temperature also somewhat affects these patterns, although less than the onset time and the nocturnal activity.

\section{Daily rhythms of locomotor activity under different photoperiods}

Next we analyzed the daily activity rhythm of L. longipalpis under constant temperature $\left(25^{\circ} \mathrm{C}\right)$ and at two different photoperiodic regimes, LD 08:16 and LD 16:08, afterwards comparing them to standard conditions (LD 12:12). Evidently, L. longipalpis adjusts, concentrating the majority of activity during the lights on/off transition, according to the length of day (Figure 2A). Intriguingly, we observed slight reduced levels of locomotor activity under LD 08:16 $\left(\mathrm{AUC}_{\mathrm{LD08:16}}=27.06, \quad \mathrm{AUC}_{\mathrm{LD12:12}}=31.10, \quad \mathrm{AUC}_{\mathrm{LD16:08}}=\right.$ 30.04). Also, the sandflies exhibited considerable changes in their patterns of anticipation (Figure 2B), a result of distinct changes in their times of onset, maximum peak or offset, according to each regime (Figure $2 \mathrm{C}$, Table 2). In fact, the differences of onset, peak and offset can reach as much as six hours comparing the regimes of LD 08:16 to LD 16:08 (Table 2). For a better understanding, we then plotted the difference between each value (onset, maximum peak and offset) and the light-dark transition $(0 \mathrm{~h})$ and noted a phase shift in all parameters that were proportional to the day length, but not exactly equal to the difference of the photoperiods (eight hours).

Curiously, there was a broader peak of locomotor activity under LD 16:08 and a narrow one under LD 08:16 (Figure 2A), suggesting different patterns of anticipation between the regimes. Even though differences of main peak and offset times compared to LD 12:12 are not apparent, under short days (LD 08:16) the sandflies displayed little anticipation (Figure 2B), initiating activity (onset time) relatively later than in other regimes (Figure $2 \mathrm{C}$, Table 2). In contrast, under long days (LD 16:08) L. longipalpis exhibited more anticipation than in any other regime (Figure 2B). This pattern of anticipation is related to an early maximum peak, which occurred almost two hours before lights off, contrary to other regimes (Figure 2C, Table 2). Similarly, the offset time under LD 16:08 was the earliest (Figure 2C, Table 2). Thus, although L. longipalpis can be entrained to any photoperiod, it indicates some peculiar differences on anticipation patterns between the regimes.

\section{Discussion}

Undoubtedly in nature, any efforts to evaluate the importance of environmental factors on insect behaviour are much more complex than under controlled laboratory conditions since these factors are multiple, oscillate simultaneously and may have distinct ranges or thresholds according to the geographical region and season. However, some important studies have been useful to better understand the influence of microclimatic influences on insect vector behavior in the field. In sandflies, both temperature and relative humidity are important influences on daily activity among different species. In Morocco, during autumn, Phlebotomus perniciosus has greater activity during twilight, when the humidity is low (40-50\%) and the temperature high $\left(>20^{\circ} \mathrm{C}\right)$, while Phlebotomus ariasi is more abundant only after midnight when humidity is high (70$80 \%)$ and temperature low $\left(15^{\circ} \mathrm{C}\right)[20]$. The importance of temperature and humidity for daily activity rhythms can vary depending upon the season in some sandfly species. For example, in Lutzomyia neivai from the province of Tucumán, Argentina, in January (summer) the nocturnal activity is mainly influenced by temperature, while in April (autumn), the humidity is the most important factor on modulation of hourly activity [21].

In the field, L. longipalpis has generally demonstrated a nocturnal pattern and higher levels of activity just a few hours before dusk [12,22,23], quite similar to our results presented here. Although some important studies have been establishing the effects of seasonal variations on L. longipalpis distribution, the consequences of seasonality on daily activity [11-15] was not explored in detail.

Our results herein, under controlled environmental conditions, showed that L. longipalpis tends to be active at night under higher $\left(30^{\circ} \mathrm{C}\right)$ rather than lower temperatures $\left(20^{\circ} \mathrm{C}\right)$, and that these patterns are mainly influenced by the time of activity increase before the lights on/off transition (onset time). However, these nocturnal activity differences are very discrete, considering only the graphs of locomotor activity, which depicts the average of several insects. Maybe the differences in the total activity of each regime and also the "smoothed" data could be decreasing the differences in the graph. Also, the time of the maximum peak of L. longipalpis observed here is pretty fixed to the first hour of the dark phase, regardless of the temperature applied. We speculate that abrupt changes in light on/off transitions could be fixing the maximum peak of activity proximate to ZT12 in these regimes, disguising possible temperature effects. Further experiments with gradual light on/off transitions (artificial "twilight transitions") may permit a better visualization of the effects of temperature on maximum peak of L. longipalpis.

Another interesting aspect observed here was the plasticity of L. longipalpis to sustain their crepuscular/nocturnal activity according to the light/dark cycle duration 
Table 2 Onset, maximum peak and offset time (Zeitgeber Time \pm SEM) and 1-way ANOVA of the experiments depicted on Figure 2

\begin{tabular}{|c|c|c|c|c|c|c|c|}
\hline & & \multicolumn{2}{|c|}{ Onset time } & \multicolumn{2}{|c|}{ Max peak time } & \multicolumn{2}{|c|}{ Offset time } \\
\hline \multirow[t]{3}{*}{ VALUES } & LD 16:08 & \multicolumn{2}{|c|}{$12.8 \pm 0.2$ Relative to lights off $(-3.2 \pm 0.2)$} & \multicolumn{2}{|c|}{$14.6 \pm 0.2$ Relative to lights off $(-1.4 \pm 0.2)$} & \multicolumn{2}{|c|}{$17.3 \pm 0.3$ Relative to lights off $(1.3 \pm 0.3)$} \\
\hline & LD 12:12 & \multicolumn{2}{|c|}{$8.7 \pm 0.3$ Relative to lights off $(-3.3 \pm 0.3)$} & \multicolumn{2}{|c|}{$12.7 \pm 0.2$ Relative to lights off $(0.7 \pm 0.2)$} & \multicolumn{2}{|c|}{$14.4 \pm 0.3$ Relative to lights off $(2.4 \pm 0.3)$} \\
\hline & LD 08:16 & \multicolumn{2}{|c|}{$6.1 \pm 0.3$ Relative to lights off $(-1.9 \pm 0.2)$} & \multicolumn{2}{|c|}{$7.9 \pm 0.3$ Relative to lights off $(-0.1 \pm 0.3)$} & \multicolumn{2}{|c|}{$10.8 \pm 0.4$ Relative to lights off $(2.8 \pm 0.4)$} \\
\hline \multirow[t]{4}{*}{ Statistical analysis } & 1-way ANOVA & $F_{2,75}=6.93$ & $P<0.01$ & $H=29.43^{b}$ & $P<0.001^{b}$ & $H=11.22^{\mathrm{b}}$ & $P<0.01^{\mathrm{b}}$ \\
\hline & LD 12:12 vs LD 08:16 & \multicolumn{2}{|c|}{$P<0.01^{\mathrm{a}}$} & \multicolumn{2}{|c|}{$\mathrm{NS}^{\mathrm{c}}$} & \multicolumn{2}{|c|}{$\mathrm{NS}^{\mathrm{c}}$} \\
\hline & LD 12:12 vs LD $16: 08$ & \multicolumn{2}{|c|}{$N S^{a}$} & \multicolumn{2}{|c|}{$P<0.001^{c}$} & \multicolumn{2}{|c|}{$P<0.05^{c}$} \\
\hline & LD $08: 16$ vs LD $16: 08$ & \multicolumn{2}{|c|}{$P<0.01^{\mathrm{a}}$} & \multicolumn{2}{|c|}{$P<0.01^{c}$} & \multicolumn{2}{|c|}{$P<0.01^{c}$} \\
\hline
\end{tabular}

aBonferroni's Multiple Comparison Test.

${ }^{\mathrm{b}}$ Kruskal-Wallis 1-way ANOVA (nonparametric test).

'Dunn's Multiple Comparison Test (nonparametric test). 
("long or short days"), demonstrating a seasonal adaptation of this species and a proper entrainment by light/ dark cycles. A detailed analysis of these results evidenced interesting aspects of $L$. longipalpis behaviour: while in short days sandflies show little anticipation, in long days the peak and also the offset of L. longipalpis activity are the earliest. Interestingly in Drosophila, the evening peak tends to anticipate more as long as the day length increases and the possible explanation for this phenomenon rely on the circadian clock machinery [24]. It has already been well established that the molecular model of the clock has several coordinated steps over 24 hours and one of the most important is the timing of PER: TIM nuclear accumulation reviewed in $[25,26]$. Shafer et al. reported that the TIM nuclear accumulation is barely phase shifted by different photoperiods, while the PER nuclear accumulation phase shift depends upon the photoperiod [24]. This unusual dynamic of nuclear accumulation between PER and TIM could be affecting some particular aspects of Drosophila locomotor activity, such as the anticipation patterns. Despite the differences between $D$. melanogaster and L. longipalpis on behaviour (diurnal vs nocturnal) and feeding habits (phytophagy vs hematophagy), the circadian expression of per and tim are quite conserved between them [26]. Thus, we are tempted to speculate that the photoperiod could act similarly on clock machinery of both species and therefore, affect their behaviour. Further immunocytochemical experiments in L. longipalpis under different photoperiods might reveal a similar scenario on this insect vector.

Thus our results and the previous in Drosophila indicated that, even though both species are able to adjust to artificial photoperiodic changes, they show some deficits in the proper entrainment, which could be caused by the lack of other environmental factors, such as temperature, which fine tunes the synchronization of the circadian clock and the behaviour of these species. Indeed, when Drosophila is submitted to light/dark and temperature cycles, the locomotor activity and the molecular oscillation of the circadian clock both improve the entrainment [27]. Curiously, if we compare the effects of temperature with those of day-length, they are pretty complementary. L. longipalpis have little anticipation under LD 08:16, while at $20^{\circ} \mathrm{C}$ they anticipate more and have a lower proportion of nocturnal activity. On the other hand, the regime of LD 16:08 is marked by a clear anticipation pattern, while under $30^{\circ} \mathrm{C}$, L. longipalpis has little anticipation (delayed on onset levels) and a higher proportion of nocturnal activity. Thus, considering that "winter-like" regimes are represented by short days (LD 08:16) and lower temperatures $\left(20^{\circ} \mathrm{C}\right)$, while "summer-like" regimes by long days (LD 16:08) and higher temperatures $\left(30^{\circ} \mathrm{C}\right)$, if we combine them according to the proper season, the overall pattern of L. longipalpis locomotor activity would be quite similar, which demonstrates a synergistic role of light/ dark cycles and temperature to the entrainment of the circadian clock of L. longipalpis, as heretofore described in many insects.

Considering that L. longipalpis is broadly distributed from Mexico to Argentina [1] and is known as a tropical insect vector, we are led to take into account the seasonal variations of temperature as the main factor, which dictates the L. longipalpis daily activity rhythms in most of these regions. In fact, in the wild, there is a positive correlation between temperature and L. longipalpis abundance [11-15]. Herein, we also observed a positive correlation, but between temperature and nocturnal activity. According to our results, a difference of $5^{\circ} \mathrm{C}$ in temperature level can produce a difference of about one hour in the onset activity and a difference of $10^{\circ} \mathrm{C}$ can double increase the proportion of nocturnal activity. Hence, we suggest that under periods of higher temperatures, as $30^{\circ} \mathrm{C}$ for example, L. longipalpis would be not only more abundant, but also more active at night, as already reported in other sandflies during warm seasons $[20,28]$. However, in other regions a bit far from the equatorial zone (e.g. Yucatan Peninsula, México; $\mathrm{N} 19^{\circ}$ or Bella Unión-Cuarein, Uruguay; S $30^{\circ}$ ), besides the differences in temperature levels, there are also differences in day length that could reach four hours from winter (10 h of daylight) to summer (14 of daylight), according to the online database of the United States Naval Observatory (USNO) Astronomy Application Department [29]. During summer (short nights) in Morocco, Guernaoui et al. described that the sandflies were active during 10 hours, whereas during autumn (longer nights), the activity extended to $14 \mathrm{~h}$ [20]. Our results show that a difference of four hours between different photoperiods (eg. LD 12:12 vs LD 16:08) produces a phase shift of locomotor activity patterns up to four hours of difference. Therefore, it seems plausible that, in the wild, even small variations of day length could entrain the behaviour of $L$. longipalpis and produce phase shifts in all parameters (onset, peak and offset) in the same time proportion.

Notwithstanding the well-established crepuscular/nocturnal behaviour of L. longipalpis in nature, previous works have reported some discrepancies in the maximum peak of activity during the night, and one of the possible reasons might be the microclimatic variations of each region $[11,12,22,23]$. However, it is very complex to establish the role of environmental factors on behaviour without taking into consideration many other factors such as humidity, odour, fasting, blood-intake and aging, which are interacting and contributing with this process as a whole. The fact that we evaluated daily activity of male L. longipalpis is interesting in some way since we could more easily avoid possible influences of insemination and blood-feeding in our results. Nevertheless, it is well known that L. longipalpis males are usually found in animal pens earlier than 
females [3,30]. Similarly, in two sympatric species from Sobral, we observed that males initiate activity somewhat earlier than females [8]. We believe that there are also sexual differences in locomotor activity of $L$. longipalpis from Lapinha [4], though it is seemingly more discrete than in sandflies from Sobral. Interestingly, although we noted small temporal differences in main activity peak among all sibling species $[4,8]$, in each, males and females tended to conserve the time of maximum peak. Thus, our results could be a good extrapolation of what is expected for L. longipalpis behaviour in general, but evidently, further experiments are imperative regarding the sex and also the complex of species of this insect vector. Regardless, our results provide interesting results that reinforce some previous findings about the effects of seasonality in sandflies. Also, our individual analysis in L. longipalpis considering the time of onset, maximum peak and offset proved to be a reliable method for the establishment of some behavioural parameters of this insect vector. Certainly, further analyses in this sense could be helpful to better determine behavioural differences of $L$. longipalpis sex, cryptic species and vectorial capacity.

\section{Conclusions}

In summary, L. longipalpis has a behavioural responsiveness to variations of temperature and photoperiod, similar to many insects, which is crucial for their physiology and ecological needs. L. longipalpis adjusts daily activity according to temperature, which is crucial in nature, to restricting this insect to warm temperatures, avoiding heat and desiccation. Moreover, L. longipalpis demonstrates a great ability of adaptation under different photoperiods sustaining the crepuscular/nocturnal activity regardless of the day length. However, under these regimes they vary in anticipation patterns, which could be due to the lack of other environmental factors, such as temperature, which acts in synergy to entrain the circadian clock and behaviour of this species. Altogether, our results can have epidemiological importance, since L. longipalpis is broadly distributed in Latin America, which means that they are probably exposed to different average temperature levels and somewhat different seasonal photoperiods. These differential environmental factors could be crucial to modulate not only $L$. longipalpis behaviour, but also the vectorial capacity according to the region and the season.

\section{Competing interest}

The authors have no competing interests.

\section{Authors' contribution}

GBSR and AAP designed the study. GBSR performed the laboratory analyses and interpretation of data. NAS reared and provided the laboratory colony sandflies. GBSR and RVB wrote the manuscript to which all authors subsequently contributed. The final version of the manuscript was approved by all authors.

\section{Acknowledgements}

We would like to thank Reginaldo P. Brazil and Antonio CA Meireles-Filho for critical comments of the manuscript. We would like to posthumously dedicate this work in memory of Alexandre Peixoto for his unconditional dedication and also for his notable contribution to the study of behaviour and evolution of $L$. longipalpis for many decades. This work was funded by the Howard Hughes Medical Institute with additional funds from CNPq, FAPERJ, Capes and FIOCRUZ.

\section{Author details}

${ }^{1}$ Laboratório de Biologia Molecular, Instituto Oswaldo Cruz, Fundação Oswaldo Cruz (FIOCRUZ), Rio de Janeiro, Brazil. ' Laboratório de Transmissores de Leishmanioses, Instituto Oswaldo Cruz, Fundação Oswaldo Cruz (FIOCRUZ), Rio de Janeiro, Brazil. Instituto Nacional de Ciência e Tecnologia em Entomologia Molecular (INCT-EM)/CNPq, Rio de Janeiro, Brazil.

Received: 14 February 2014 Accepted: 6 June 2014

Published: 19 June 2014

\section{References}

1. Young DG, Duncan MA: Guide to the identification and geographic distribution of Lutzomyia sandflies in Mexico, the West Indies, Central and South America (Diptera: Psychodidae). Mem Amer Ent Inst 1994, 54:1-881.

2. Deane LM, Deane MP: Observações sobre abrigos e criadouros de flebótomos do Noroeste do Estado do Ceará. Rev Bras Malariol Doenç Trop 1957, 9:225-246

3. Morrison AC, Ferro C, Pardo R, Torres M, Wilson ML, Tesh RB: Nocturnal activity patterns of Lutzomyia longipalpis (Diptera: Psychodidae) at an endemic focus of visceral leishmaniasis in Colombia. J Med Entomol 1995, 32:605-617.

4. Meireles-Filho AC, da S Rivas GB, Gesto JS, Machado RC, Britto C, De Souza NA, Peixoto AA: The biological clock of an haematophagous insect: locomotor activity rhythms, circadian expression and downregulation after a bloodmeal. FEBS Lett 2006, 580:2-8.

5. Meireles-Filho AC, Amoretty PR, Souza NA, Kyriacou CP, Peixoto AA: Rhythmic expression of the cycle gene in a hematophagous insect vector. BMC Mol Biol 2006, 580:2-8.

6. Bauzer $L G$, Souza NA, Maingon RD, Peixoto AA: Lutzomyia longipalpis in Brazil: a complex or a single species? A mini-review. Mem Inst Oswaldo Cruz 2007, 102:1-12.

7. Araki AS, Ferreira GE, Mazzoni CJ, Souza NA, Machado RC, Bruno RV, Peixoto AA: Multilocus analysis of divergence and introgression in sympatric and allopatric sibling species of the Lutzomyia longipalpis complex in Brazil. PLoS Negl Trop Dis 2013, 7(10):e2495.

8. Rivas GBS, Souza NA, Peixoto AA: Analysis of the activity patterns of two sympatric sandfly siblings of the Lutzomyia longipalpis species complex from Brazil. Med Vet Entomol 2008, 22:288-290.

9. Clements AN: The Biology of Mosquitoes. Vol. 2. Sensory Reception and Behaviour. New York: CABI Publishing; 1999.

10. Saunders DS: Insect Clocks. Amsterdam: Elsevier; 2002.

11. Sherlock IA, Guitton N: Observações sobre calazar em Jacobina, Bahia. IV. Variação horária e estacional de Phlebotomus longipalpis. Rev Bras Malar 1969, 21:715-727.

12. Rebêlo JMM: Hourly frequency and seasonality of Lutzomyia longipalpis (Diptera: Psychodidae: Phlebotominae) on São Luís Island, Maranhão, Brazil. Cad Saúde Pública 2001, 17(1):221-227.

13. Barata RA, Da Silva JCF, Fortes-Dias CL, Da Costa RT, Fortes-Dias CL, Da Silva JC, De Paula EV, Prata A, Monteiro EM, Dias ES: Phlebotomine sand flies in Porteirinha, an area of American visceral leishmaniasis transmission in the state of Minas Gerais, Brazil. Mem Inst Oswaldo Cruz 2004, 99:481-487.

14. Resende MC, Camargo MC, Vieira JR, Nobi RC, Porto MN, Oliveira CD, Pessanha JE, Cunha Mda C, Brandão ST: Seasonal variation of Lutzomyia longipalpis in Belo Horizonte, State of Minas Gerais. Rev Soc Bras Med Trop 2006, 39(1):51-55.

15. Barata RA, Apolinário EC: Sandflies (Diptera: Psychodidae) from caves of the quartzite Espinhaço Range, Minas Gerais. Brazil Mem Inst Oswaldo Cruz 2012, 107(8):1016-1020.

16. Souza NA, Andrade-Coelho CA, Barbosa AF, Vilela ML, Rangel EF, Deane MP: The influence of sugars and amino acids on the blood-feeding behaviour, oviposition and longevity of laboratory colony of Lutzomyia longipalpis (Lutz \& Neiva, 1912) (Diptera: Psychodidae, Phlebotominae). Mem Inst Oswaldo Cruz 1995, 90(6):751-757. 
17. Schmid B, Helfrich-Förster C, Yoshii T: A new ImageJ plugin "ActogramJ" for chronobiological analyses. J Biol Rhythms 2011, 26:464-467.

18. Stoleru D, Peng Y, Agosto J, Rosbash M: Coupled oscillators control morning and evening locomotor behaviour of Drosophila. Nature 2004, 431(7010):862-868.

19. Sheeba V, Fogle KJ, Holmes TC: Persistence of morning anticipation behavior and high amplitude morning startle response following functional loss of small ventral lateral neurons in Drosophila. PLOS One 2010, 5(7):e11628.

20. Guernaoui S, Boussaa S, Pesson B, Boumezzough A: Nocturnal activity of phlebotomine sandflies (Diptera: Psychodidae) in a cutaneous leishmaniasis focus in Chichaoua, Morocco. Parasitol Res 2006, 98(3):184-188.

21. Fuenzalida AD, Quintana MG, Salomón OD, De Grosso MS: Hourly activity of Lutzomyia neivai in the endemic zone of cutaneous leishmaniasis in Tucumán, Argentina: preliminary results. Mem Inst Oswaldo Cruz 2011, 106(5):635-638.

22. Quinnell RJ, Dye C: An Experimental-Study of the Peridomestic Distribution of Lutzomyia-Longipalpis (Diptera, Psychodidae). Bull Entomol Res 1994, 84(3):379-382.

23. Zeledon R, Murillo J, Gutierrez H: Observaciones sobre la ecología de Lutzomyia longipalpis (Lutz \& Neiva, 1912) y posibilidades de existencia de leishmaniasis visceral en Costa Rica. Mem Inst Oswaldo Cruz 1984, 79:455-459.

24. Shafer OT, Levine JD, Truman JW, Hall JC: Flies by night: effects of changing day length on Drosophila's circadian clock. Curr Biol 2004, 14(5):424-432.

25. Hardin PE: Molecular genetic analysis of circadian timekeeping in Drosophila. Adv Genet 2011, 74:141-173.

26. Meireles-Filho AC, Kyriacou CP: Circadian rhythms in insect disease vectors. Mem Inst Oswaldo Cruz 2013, 108(Suppl I):48-58,

27. Yoshii T, Vanin S, Costa R, Helfrich-Förster C: Synergic entrainment of Drosophila's circadian clock by light and temperature. J Biol Rhythms 2009, 24(6):452-464.

28. Galati EAB, Nunes VL, Boggiani PC, Dorval MEC, Cristaldo G, Rocha HC, Oshiro ET, Damasceno-Júnior GA: Phlebotomines (Diptera: Psychodidae) in forested areas of the Serra da Bodoquena, state of Mato Grosso do Sul, Brazil. Mem Inst Oswaldo Cruz 2006, 101:175-193.

29. United States Naval Observatory (USNO) Astronomy Application Department. Duration of Daylight/Darkness Table for One Year. [http://aa.usno.navy.mil/data/docs/Dur_OneYear.php]

30. Kelly DW, Dye C: Pheromones, kairomones and aggregation dynamics of the sandfly Lutzomyia longipalpis. Anim Behav 1997, 53:721-731.

doi:10.1186/1756-3305-7-278

Cite this article as: Rivas et al: Effects of temperature and photoperiod on daily activity rhythms of Lutzomyia longipalpis (Diptera: Psychodidae).

Parasites \& Vectors 2014 7:278.

\section{Submit your next manuscript to BioMed Central and take full advantage of:}

- Convenient online submission

- Thorough peer review

- No space constraints or color figure charges

- Immediate publication on acceptance

- Inclusion in PubMed, CAS, Scopus and Google Scholar

- Research which is freely available for redistribution 